\title{
Design of Demerit Control Charts with Fuzzy c-Means Clustering and an Application in Textile Sector
}

\author{
Hulya Yılmaz ${ }^{1}$, Seda Yanık² \\ ${ }^{1}$ Kirklareli University / Academic Evaluation and Quality Improvement Coordinatorship / Kirklareli, Turkey \\ ${ }^{2}$ Istanbul Technical University / Department of Industrial Engineering / İstanbul, Turkey
}

Corresponding Author: Hulya Yilmaz, hulyayilmaz@klu.edu.tr

\begin{abstract}
Companies use process control to detect and prevent defects in production. One of the most commonly used technique is the control charts. To control multiple dimensions of quality on one control chart, multivariable control charts, control charts for attributes and demerit control charts are widely used. In this study, we use demerit control charts to monitor multiple defect types and propose to employ the fuzzy c-means method to cluster the defect types based on pre-specified criteria. The criteria are chosen to represent the severity of defect types and specified as (i) number of scraps, (ii) number of reworks and (iii) time of the rework. In order to test the proposed method, $\mathrm{u}$ and $\mathrm{c}$ attribute control charts and demerit control charts for six instances in a textile company are used and compared. It is observed that both the scrap and the repair rates are decreased when the proposed method of the demerit control chart is used.
\end{abstract}

\author{
ARTICLE HISTORY \\ Received: 18.09.2019 \\ Accepted: 12.05.2020
}

\section{KEYWORDS}

Attribute control charts, Demerit control charts, Fuzzy clustering, Fuzzy demerit control charts, Process control

\section{INTRODUCTION}

Today, the textile sector is one of the largest sectors in the world. In order to ensure continuity in the textile sector, one of the objectives that should be considered is to reduce quality-related costs such as prevention, appraisal, internal and external quality costs. To achieve this, the use of statistical process control (SPC) techniques is required due to the complexity of the product structures and the presence of multiple factors that affect quality.

The main purpose of SPC is to identify the source of the problems in the process and to prevent the production of nonconforming units. SPC has significant impacts such as decreases in all quality-related costs and increases in productivity. Seven basic SPC tools are used: check sheet, histogram, Pareto chart, cause-and-effect diagram, defect concentration diagram, scatter diagram, control chart $[1,2]$. These methods are essential for making qualified production in many sectors, including textile production companies [3]. Control charts are one of the commonly used statistical process control techniques for these purposes and are important for process monitoring. The implementation of SPC techniques is beneficial to the service sector and manufacturing companies [4]. Control charts can be used to check whether the process is under control [5]. When there are out-of-control signals in the control charts, the process should be stopped and examined to eliminate assignable causes. Assignable causes may result in process shifts and/or excess variability which is not inherent to the process. The shifts and the excess variability can be reduced when the control charts are used systematically.

Univariate control charts monitor a single quality characteristic, whereas multivariate control charts monitor one or more quality characteristics. Multivariable control charts can be used in order to examine the relationships between quality characteristics and control the multiple quality dimensions in one chart [6]. Multivariate control charts can be more effect in detecting the out-of-control processes than the traditional ones. However, they are limited to aggregate information of only a few process/product variables in one control chart. Moreover, it is difficult to interpret the out-of-control signals because an out-of-control point can occur due to several situations: i) one out-of-control process variable, ii) two or more variables acting together or iii) a change in the covariance

To cite this article: Yilmaz H. Yanik S. 2020. Design of Demerit Control Charts with Fuzzy c-Means Clustering and an Application in Textile Sector. Tekstil ve Konfeksiyon, 30(2), 117-125. 
matrix. Thus, further analysis is required to identify what really happened in the process. Another drawback of multivariate charts is that it requires high-level knowledge of mathematics and statistics. In the manufacturing industry, attribute control charts such as p, c, and u charts are also used to identify and eliminate the causes of various types of defects [7]. The $\mathrm{p}$ control chart and the demerit control chart can be both used to control a high number of quality dimensions in one chart. The $\mathrm{p}$-control chart and the demerit control chart were compared by Rasouli and Zarei (2016). Results indicated that the demerit control chart was more sensitive than the p-control chart [8].

In the literature, there exist empirical studies on the demerit control charts which were applied in different sectors. For example, supplier's performance monitoring [9], monitoring and reducing patient dissatisfaction in hospital [8], the production process of plastic buttons [5], injectionmolding production lines [10], garment and footwear industries [11], the reflow soldering and wave-soldering processes [12]. Moreover, the fuzzy set theory has also been used to deal with vague data and increase the sensitivity of the control charts. In Ref. [13], a fuzzy control chart based on experts' quality scoring was proposed. They focused on unobservable and variable product characteristics. Fuzzy numbers were used to capture uncertainties in environmental data or measurement data [5]. To address the difficulty of assigning weights to each category in demerit control charts, a linguistic variable to represent the importance and severity is proposed to be more suitable in Ref. [14]. In Ref. [15] a fuzzy process control method in which fuzzy control charts were employed to monitor a process was proposed.

Using traditional demerit control charts, defects are grouped into defect classes based on their importances/ severities by judgement. Then, weights representing the importance levels are assigned to each defect class. The weights which represent the importance of the defects are also identified by judgement and typically represented by a scale. For example, the defect classes with increasing importance are assigned with weights of 1, 10, 50 and 100, etc. [1]. These weights are used together with the defect numbers of classes in order to calculate the demerit points. Assignment of the defects to different defect classes and the demerit points have a significant effect on identifying the assignable causes when using demerit control charts. Thus, we propose to group the defects and calculate the demerit points using some measurable pre-specified criteria and a structured methodology. To achieve this, we propose to use the demerit control chart with fuzzy clustering which is based on the fuzzy set theory.

In this study, we use the fuzzy c-means method to cluster the defect types based on three criteria representing the importance/severity of the defect types. Then, demerit control charts were set up by using the cluster membership levels of each defect while calculating the demerit points. Finally, the proposed method, which combines the fuzzy cmeans and the demerit control charts, was tested by $\mathrm{u}, \mathrm{c}$ and demerit control charts for 6 different instances in a textile company. The results showed that demerit control charts with fuzzy c-means were more sensitive to detect the assignable causes in the process. As well, the scrap and the repair rates were decreased when the proposed method of demerit control chart was used [16]. In the literature, some studies combine clustering methods with SPC charts; however, to the best of our knowledge, there exists no study which combines the fuzzy clustering method and demerit chart in order to identify the defect groups for demerit control charts.

This study is organized as follows: Section 2 presents the preliminaries and the material method. Section 3 describes the case study and presents the results and discussions. Finally, Section 4 discusses the conclusion.

\section{MATERIAL AND METHOD}

In the following subsections, firstly fuzzy c-means method is presented. The fuzzy c-means is used to cluster the defect types and to calculate the membership values of each defect to one/several cluster(s). Then, the preliminaries related to the demerit control charts are described. Finally, the proposed methodology is presented. In the proposed method, the demerit control charts are designed precisely using a defect clustering method, namely fuzzy c-means.

\subsection{Fuzzy c-Means Clustering}

When a crisp clustering method is used, the results are obtained such that each data belongs to one cluster. However, when a data is similar in properties to more than one cluster, it is difficult to identify which cluster to assign to. The main difference between classical and fuzzy clustering is that a data point in fuzzy clustering can belong to more than one cluster [17].

The fuzzy c-means (FCM) algorithm aims to divide the elements of a dataset $X=\left\{x_{1}, x_{2}, \ldots, x_{n}\right\}$ into fuzzy clusters according to the given criteria. Given a finite set of data, the algorithm returns a list of c cluster centers $\left\{c_{1}, c_{2}, \ldots, c_{n}\right\}$ and a partition matrix $U=\mu_{i j}$, where each element $\mu_{i j}$ represents the degree to which element $x_{i}$ belongs to cluster $c_{j}$ by minimizing the objective function.

In the fuzzy c-means (FCM) algorithm, each element can belong to a cluster with a degree in between 0 and 1 and the sum of all membership degrees of an element should be equal to 1 . These conditions are satisfied using the Equations (1) and (2),

$0 \leq \mu_{i j} \leq 1, \quad \forall i j j$
$\sum_{j=1}^{c} \mu_{i j}=1, \quad \forall i$

Fuzzy c-means is based on the minimization of the objective function given in Equation (3),

$\sum_{i=1}^{n} \sum_{j=1}^{c} \mu_{i j}^{m}\left\|x_{i}-c_{j}\right\|^{2}$ 
where $m$ is a real number larger than $1, x_{i}$ is the $i^{\text {th }}$ data point, $c_{i}$ represents the cluster center, $\mu_{i j}$ is the membership value which represents the degree of membership of $x_{i}$ to cluster $i$ [17]. Thus, the objective is to minimize the sum of weighted distances of all elements to all cluster centers where weights are the membership degrees.

In our study, prior to the fuzzy c-means clustering analysis, the data were standardized using min-max normalization given in Equation (4) between the range 0 and 1.

$X^{*}=\frac{X_{i}-X_{\min }}{X_{\max }-X_{\min }}$

where $X^{*}$ is the standardized data, $X_{i}$ is $i^{\text {th }}$ data, $X_{\min }$ and $X_{\max }$, are the minimum and maximum values of the data set respectively.

The steps of the fuzzy c-means clustering procedure are as follows [17]:

1. Set $c$, number of clusters, where $c$ is $(2<c<n)$ and $n$ is the number of data points. Choose a value for parameter $m$ and then initialize the partition matrix $U^{(0)}$. Continue iteratively where $k$ are the iteration steps, $k=0,1,2, \ldots$

2. At $k$-th step: Compute $C_{j}$, center vectors with $U^{(k)}$ using Eq. 5:

$C_{j}=\frac{\left(\sum_{i=1}^{n} \mu_{i j}^{m} X_{i}\right)}{\sum_{i=1}^{n} \mu_{i j}^{m}}$

3. Update the partition matrix $U^{(k)}, U^{(k+1)} \mathrm{Eq}$.

$u_{i j}=\left(1 / \sum_{t=1}^{c}\left(\frac{\left\|X_{i}-C_{j}\right\|}{\left\|X_{i}-C_{t}\right\|}\right)^{m-1}\right)$

4. If $\left\|U^{(k+1)}-U^{(k)}\right\|<\delta$ then STOP; otherwise, return to step 2 .

\subsection{Demerit Control Charts}

Demerit control charts are used to monitor different types of defects in complex products. Four classes which represent different importance levels of defects have been found satisfactory for many kinds of product [18]. The defect classes are defined as "Class A Defects-Very Serious", "Class B Defects-Serious", "Class C DefectsModerately Serious", and "Class D Defects-Minor" [1]. The traditional approach is to plot the demerit statistic on a control chart with 3-sigma control limits where demerit statistic is obtained using the weighted demerit points of different defect classes [19,20].

$c_{i A}, c_{i B}, c_{i C}$, and $c_{i D}$ represent the number of Class A, Class $\mathrm{B}$, Class C, and Class D defects in the $i^{\text {th }}$ inspection unit, respectively. Each class of defect is independent. $d_{i}$ is defined as the number of demerits in the inspection unit by Equation (7).

$$
d_{i}=100 * c_{i A}+50 * c_{i B}+10 * c_{i C}+c_{i D}
$$

where the demerit weights are 100, 50, 10, and 1 for Class A, B, C, and D respectively. These weight values are used widely in practice. $n$ is defined as the total number of inspection units. $d_{i}$ is the weighted total number of demerits in inspection unit $i$. The number of demerits per unit is defined by Equations (8).

$u_{i}=\frac{\mathrm{D}}{\mathrm{n}}$

where $D=\sum_{i=1}^{n} d_{i}$ is the total number of demerits in all $n$ inspection units. $u_{i}$ is the number of demerits per unit $i$. The demerit control chart can be obtained by Equations (9)-(11).

$U C L=\bar{u}+3 \sigma ; \quad C L=\bar{u} ; \quad L C L=\bar{u}-3 \sigma$
$\bar{u}=100 * u_{A}+50 * u_{B}+10 * u_{C}+u_{D}$
$\sigma=\sqrt{\left(100^{2} * u_{A}+50^{2} * u_{B}+10^{2} * u_{C}+u_{D}\right) / n}$

where $\bar{u}$ is the center line of the demerit chart, $\sigma$ is the standard deviation, $u_{A}, u_{B}, u_{C}$, and $u_{D}$ represent the average number of Class A, Class B, Class C, and Class D defects per unit. The values of $u_{A}, u_{B}, u_{C}, u_{D}$, and are obtained from the analysis of preliminary data, taken when the process is supposedly operating in control [11].

\subsection{Demerit Control Charts with Fuzzy c-Means Clustering}

When using traditional demerit control charts, the clustering of the defects and the weight assignments are typically made by expert judgement. When there exists a high number of defects and various criteria affecting the severity of the defects, the judgement of the expert is limited and can be erroneous [20]. Moreover, it may not be easy to match the severity of a specific defect with the labels of the defect classes. For example, it is not easy to judge the class of a defect which is not as serious as "Class A Defects (i.e. very serious defects)" but more serious than "Class B Defects (i.e. serious defects). In this sense, a more flexible clustering approach may improve the accuracy of the results.

To overcome the limitations of the traditional approach, we propose to design the demerit control charts using the fuzzy c-means clustering method. The clustering method aims to cluster the defect types into classes that will be used by the demerit control charts. In fuzzy clustering, each defect can belong to more than one cluster with some membership value between 0 and 1 .

When demerit control charts are used with fuzzy c-means clustering, the demerit points are calculated with the cluster membership level of defects to classes added to the class weights and the number of defects. The defect points per product are obtained using Equation (12).

where $X_{t A}$ is the number of defect type $t$ which is classified as an A-class defect and $\mu_{t A}$ is the membership value of defect type $t$ to defect class A. Notation is used similarly for the other defect classes of B, C, and D. 
To calculate the control limits of the fuzzy demerit control diagram, standard deviation, $\sigma$, is calculated using Equation (13).

The contribution of this study can be summarized as follows: When using demerit control charts, the assignment of defects to different classes (i.e. Class A, Class B, etc.) is vague. In this study we use a fuzzy clustering framework for specifying the classes of the defects based on the severeness of the defects using three criteria; rework quantities occurring due to each defect, scrap quantities occurring due to each defect and the time of the rework. Fuzzy clustering results in a clustering scheme where each defect can be assigned to more than one class. When using traditional demerit control charts, the assignment of defects to different classes (i.e. Class A, Class B, etc.) is vague. In the demerit system, each class is weighed using qualitative scores. Thus, the judgement of the defect assignments to classes affects the result significantly. Using a fuzzy assignment of defects to classes will incorporate more information in the assignment and help to make the judgement of the vagueness of the assignments easier. Thus, the demerit system will become more sensitive. All in all, we propose a clustering approach for identifying the demerit classes of the defects, moreover, we use fuzzy set theory to deal with the vagueness of the assignment of defects to classes. To the best of our knowledge, this approach has not been studied in the literature before.

\section{RESULTS AND DISCUSSION}

The case study was conducted in a textile garment manufacturer. To test the proposed method, six instances are examined. Two types of customer order as low quantity and high quantity from three different product types are used.
The three product types are dress, blouse and skirt. Then, the manufacturing process for these six instances was monitored. u, c, and demerit control charts with fuzzy cmeans were established and compared. The properties of the six different process instances used in the case study are summarized in Table 1. Then, the steps of the case study are given in Figure 1.

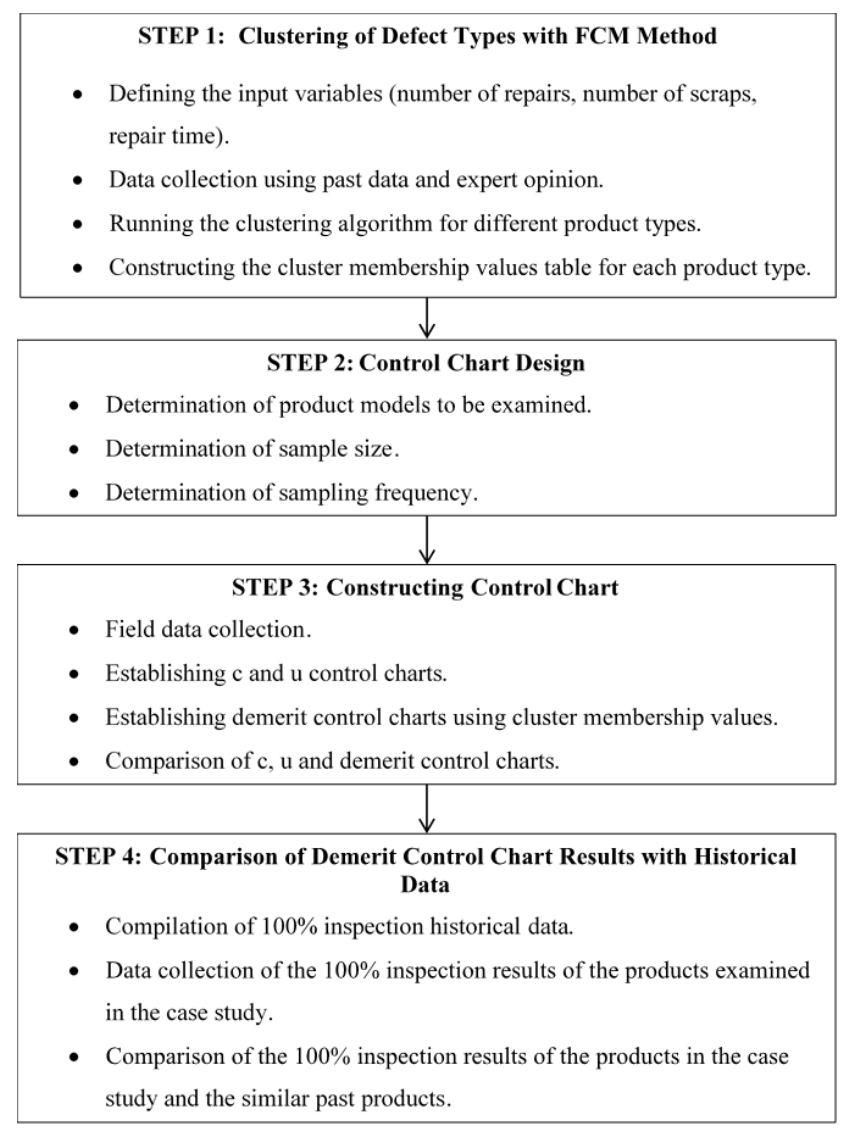

Figure 1. Flowchart of the case study

$u=\frac{\left(100 *\left(\sum_{t \in A} X_{t A} * \mu_{t A}\right)+50 *\left(\sum_{t \in B} X_{t B} * \mu_{t B}\right)+10 *\left(\sum_{t \in C} X_{t C} * \mu_{t C}\right)+\left(\sum_{t \in D} X_{t D} * \mu_{t D}\right)\right)}{n}$
$\sigma=\sqrt{\frac{\left(100^{2} *\left(\sum_{t E A} u_{A} * \mu_{t A}\right)+50^{2} *\left(\sum_{t \in B} u_{B} * \mu_{t B}\right)+10^{2} *\left(\sum_{t E C} u_{C} * \mu_{t C}\right)+\left(\sum_{t E D} u_{D} * \mu_{t D}\right)\right)}{n}}$

Table 1. Information related to six process instances in the case study

\begin{tabular}{|c|c|c|c|c|}
\hline $\begin{array}{l}\text { Product } \\
\text { type }\end{array}$ & $\begin{array}{c}\text { Order } \\
\text { quantity }\end{array}$ & $\begin{array}{c}\text { Duration of } \\
\text { production time }\end{array}$ & $\begin{array}{c}\text { Number of } \\
\text { employees/day }\end{array}$ & Sample size/day \\
\hline Dress $1^{\text {st }}$ & 2160 pcs. & 7 days & 54 & 50 \\
\hline Dress $2^{\text {nd }}$ & 6200 pcs. & 13 days & 53 & 50 \\
\hline Blouse $1^{\text {st }}$ & 2100 pcs. & 5 days & 31 & 50 \\
\hline Blouse $2^{\text {nd }}$ & 7200 pcs. & 15 days & 45 & 50 \\
\hline Skirt $1^{\text {st }}$ & 1600 pcs. & 5 days & 21 & 50 \\
\hline Skirt $2^{\text {nd }}$ & 5230 pcs. & 10 days & 37 & 50 \\
\hline
\end{tabular}




\subsection{Fuzzy c-Means for Clustering the Defect Types}

Prior to the process control, the defect types to be used in the demerit charts were clustered using a dataset including three criteria via the fuzzy c-means method. Three criteria, namely scrap quantities, rework quantities and the time of the rework, are used as input variables of the fuzzy c-means to group the defect types of each product type. Scrap and rework quantities were obtained from the recorded past data. The time of rework for each defect type was identified by the opinions of the workers doing the rework and the quality control experts. The number of defects clustered for the three product types; blouses, skirts, and dresses respectively are as follows: 60, 50, 60 .

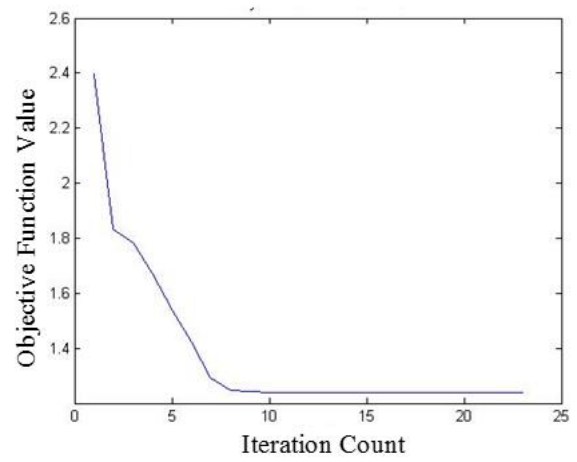

The defects were clustered using the fuzzy c-means algorithm in MATLAB 2010a with the Fuzzy Logic Toolbox. In Figure 2, the results of clustering for the dress models are given. On the left of the figure, the change in the objective function with respect to the iteration numbers is shown. On the right, the clusters and their centers are depicted.

By comparing the values of the cluster centers for each criterion, namely rework quantities, scrap quantities and the time of rework, the clusters, and the defect classes are matched and named as given Table 2. For a process instance of the product type dress, membership values of the defects to four classes are given in Table 3.

In Table 4, assignments of defects to the classes to which its membership is the highest are shown.

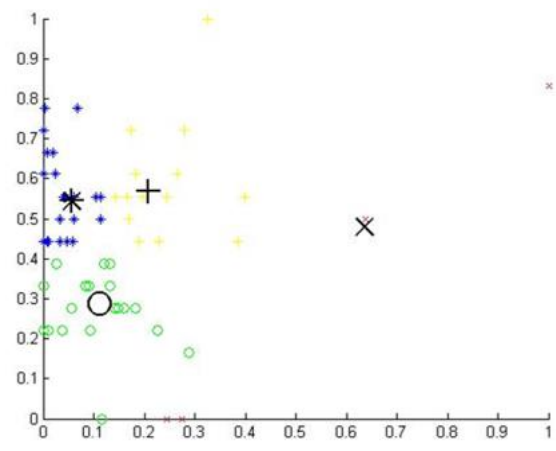

Figure 2. The results of clustering for a dresses model

Table 2. Cluster and defect class matching for an instance of dress

\begin{tabular}{ccccc}
\hline Defect class & Cluster-ID & Rework quantities & Scrap quantities & The time of the rework \\
\hline A & 3 & High & Middle & High \\
B & 1 & High & High & Low \\
C & 2 & Middle & Low & Low \\
D & 4 & Low & Low & High \\
\hline
\end{tabular}

Table 3. Membership values of the defects for an instance of dress

\begin{tabular}{cccccccccc}
\hline $\begin{array}{c}\text { Defect } \\
\text { types }\end{array}$ & Cluster 1 & Cluster 2 & Cluster 3 & Cluster 4 & $\begin{array}{c}\text { Defect } \\
\text { types }\end{array}$ & Cluster 1 & Cluster 2 & Cluster 3 & Cluster 4 \\
\hline $\mathbf{1}$ & 0.0088 & 0.0757 & 0.2537 & 0.6617 & $\mathbf{4 5}$ & 0.0072 & 0.2577 & 0.4385 & 0.2966 \\
$\mathbf{2}$ & 0.0004 & 0.0071 & 0.0192 & 0.9732 & $\mathbf{4 6}$ & 0.0021 & 0.9412 & 0.0266 & 0.0301 \\
$\mathbf{3}$ & 0.0025 & 0.0252 & 0.8393 & 0.1331 & $\mathbf{4 7}$ & 0.0039 & 0.0444 & 0.1389 & 0.8128 \\
$\mathbf{4}$ & 0.0048 & 0.2142 & 0.1501 & 0.6309 & $\mathbf{4 8}$ & 0.0098 & 0.7830 & 0.0799 & 0.1274 \\
$\mathbf{5}$ & 0.0063 & 0.2167 & 0.1341 & 0.6429 & $\mathbf{4 9}$ & 0.0021 & 0.0347 & 0.2399 & 0.7232 \\
$\mathbf{6}$ & 0.4113 & 0.2315 & 0.1818 & 0.1754 & $\mathbf{5 0}$ & 0.4849 & 0.1965 & 0.1627 & 0.1559 \\
$\mathbf{7}$ & 0.0018 & 0.0289 & 0.1730 & 0.7963 & $\mathbf{5 1}$ & 0.0059 & 0.2134 & 0.1331 & 0.6475 \\
$\mathbf{8}$ & 0.0055 & 0.6068 & 0.1515 & 0.2362 & $\mathbf{5 2}$ & 0.0076 & 0.6753 & 0.0994 & 0.2176 \\
$\mathbf{9}$ & 0.0049 & 0.2098 & 0.1412 & 0.6441 & $\mathbf{5 3}$ & 0.0058 & 0.2127 & 0.1330 & 0.6485 \\
$\mathbf{1 0}$ & 0.0022 & 0.0328 & 0.7640 & 0.2010 & $\mathbf{5 4}$ & 0.0093 & 0.0790 & 0.2466 & 0.6652 \\
$\mathbf{1 1}$ & 0.0014 & 0.0186 & 0.9058 & 0.0742 & $\mathbf{5 5}$ & 0.0041 & 0.8894 & 0.0521 & 0.0545 \\
$\mathbf{1 2}$ & 0.0029 & 0.0754 & 0.2218 & 0.6999 & $\mathbf{5 6}$ & 0.0262 & 0.2522 & 0.5076 & 0.2140 \\
$\mathbf{1 3}$ & 0.0004 & 0.0065 & 0.0179 & 0.9753 & $\mathbf{5 7}$ & 0.0013 & 0.0343 & 0.0593 & 0.9051 \\
$\mathbf{1 4}$ & 0.0050 & 0.0563 & 0.1453 & 0.7933 & $\mathbf{5 8}$ & 0.0027 & 0.0426 & 0.5573 & 0.3974 \\
$\mathbf{1 5}$ & 0.1484 & 0.1807 & 0.3932 & 0.2777 & $\mathbf{5 9}$ & 0.0026 & 0.9210 & 0.0293 & 0.0471 \\
$\mathbf{\ldots}$ & & & & & $\mathbf{6 0}$ & 0.0023 & 0.8957 & 0.0380 & 0.0640 \\
\hline
\end{tabular}




\subsection{Monitoring the Process Using Control Charts}

In the field study, data was collected with a sampling interval of one hour and a sample size of 5. A total of 250 samples was taken for 5 days for each of the 6 case instances examined. In the demerit charts, demerit points were calculated using the cluster membership levels of each defect, weights and the number of defects of each class. The total membership values of all defects to each classes were given for one of the case instances in Table 5 .

The obtained control charts for the low and high quantity order of the dress and blouse models were given in Figures
3, 4, 5, and 6 respectively. During the production, the process averages were improved in time due to the learning effect. Thus, at the time point where the improvement was observed on the control charts, the process parameters were updated and revised control limits were established. We observed that there exist several out of control points at the demerit charts in Figure 3(a), 4(a), 5(a), and 6(a). However, c-charts in Figure 3(b), 4(b), 5(b), 6(b) and the u-charts in Figure 3(c), 4(c), 5(c), 6(c) did not result in any out-ofcontrol signals.

Table 4. The defects and their classes based on the maximum membership value assignment for an instance of dress

\begin{tabular}{|c|c|c|c|}
\hline Class A & Class B & Class C & Class D \\
\hline $\begin{array}{l}\text { lining too full or too tight, } \\
\text { pocket-open stitch, placket, } \\
\text { side seam, hole, zipper, } \\
\text { needle cuts, needle pinch, } \\
\text { side seam uneven, elasticity, } \\
\text { components not symmetrical, } \\
\text { overlock, collar-open stitch, } \\
\text { sleeve hole }\end{array}$ & $\begin{array}{l}\text { paint/printing, stain, } \\
\text { needle failure, } \\
\text { different shades } \\
\text { within the same garment }\end{array}$ & $\begin{array}{l}\text { uneven sleeve length, } \\
\text { skip stitch, button, } \\
\text { bottom hem- open stitch, } \\
\text { seam unravelling, } \\
\text { ruffle, buttonhole, } \\
\text { sleeve opening, slash, } \\
\text { sleeve band-open stitch, } \\
\text { pipe, fabric, waistband, } \\
\text { pintuck, open stitch, } \\
\text { pleat, unraveled, } \\
\text { run of stitch, care label }\end{array}$ & $\begin{array}{l}\text { lining-covering stitch, } \\
\text { trimming, hook, lace, } \\
\text { stitching of bottom hem, } \\
\text { broken stitch, defective snap, } \\
\text { seam slippage, drop stitch, } \\
\text { zipper-seam slippage, } \\
\text { label, seam puckering, } \\
\text { belt, sleeve-seam slippage, } \\
\text { sleeve-open stitch, dart, } \\
\text { uneven cuff width, yoke, } \\
\text { embroidery, covering stitch, } \\
\text { stopper, lace broken stitch, } \\
\text { collar-seam slippage }\end{array}$ \\
\hline
\end{tabular}

Table 5. Data of the $1^{\text {st }}$ Dress with 50 subgroups (subgroup size of 5)

\begin{tabular}{|c|c|c|c|c|c|c|c|c|c|c|c|}
\hline \multirow[t]{2}{*}{ Sample } & \multirow[t]{2}{*}{$\begin{array}{c}\text { \# of } \\
\text { defects }\end{array}$} & \multicolumn{4}{|c|}{$\begin{array}{l}\text { Sum of Membership Value *\# of } \\
\text { Defects of all defect types } \\
\text { [e.g. }\left(\sum_{t \in A} X_{t A} * \mu_{t A}\right) \text { for Class A] }\end{array}$} & \multirow[t]{2}{*}{ Sample } & \multirow[t]{2}{*}{$\begin{array}{c}\text { \# of } \\
\text { defects }\end{array}$} & \multicolumn{4}{|c|}{$\begin{array}{l}\text { Sum of Membership Value *\# of } \\
\text { Defects of all defect types } \\
\text { [e.g. }\left(\sum_{t \in A} X_{t A} * \mu_{t A}\right) \text { for Class A] }\end{array}$} \\
\hline & & $\mathbf{A}$ & B & $\mathbf{C}$ & D & & & $\mathbf{A}$ & B & $\mathrm{C}$ & D \\
\hline 1 & 4 & 0.071 & 0.002 & 0.983 & 2.944 & 35 & 2 & 0.131 & 0.013 & 0.781 & 1.076 \\
\hline 2 & 4 & 0.109 & 0.005 & 1.824 & 2.062 & 36 & 2 & 0.150 & 0.703 & 0.995 & 0.153 \\
\hline 3 & 3 & 0.103 & 0.008 & 2.730 & 0.159 & 37 & 2 & 0.590 & 0.006 & 0.963 & 0.441 \\
\hline 4 & 4 & 0.103 & 0.008 & 1.856 & 2.033 & 38 & 2 & 0.020 & 0.992 & 0.008 & 0.981 \\
\hline 5 & 5 & 3.847 & 0.016 & 0.279 & 0.858 & 39 & 3 & 0.227 & 0.007 & 0.263 & 2.503 \\
\hline 6 & 4 & 0.999 & 0.009 & 2.744 & 0.248 & 40 & 1 & 0.512 & 0.009 & 0.241 & 0.238 \\
\hline 7 & 4 & 0.103 & 1.001 & 2.749 & 0.147 & 41 & 1 & 0.619 & 0.025 & 0.154 & 0.202 \\
\hline 8 & 3 & 0.655 & 0.008 & 1.904 & 0.432 & 42 & 2 & 0.601 & 0.004 & 0.100 & 1.295 \\
\hline 9 & 4 & 0.922 & 0.737 & 0.770 & 1.571 & 43 & 2 & 0.587 & 0.005 & 0.964 & 0.445 \\
\hline 10 & 2 & 0.529 & 0.009 & 0.246 & 1.216 & 44 & 1 & 0.508 & 0.026 & 0.252 & 0.214 \\
\hline 11 & 3 & 0.088 & 0.006 & 2.787 & 0.118 & 45 & 2 & 0.560 & 0.994 & 0.045 & 0.400 \\
\hline 12 & 4 & 0.256 & 0.011 & 2.929 & 0.804 & 46 & 1 & 0.035 & 0.002 & 0.905 & 0.058 \\
\hline 13 & 4 & 0.124 & 0.006 & 0.972 & 2.898 & 47 & 1 & 0.016 & 0.001 & 0.963 & 0.019 \\
\hline 14 & 6 & 3.642 & 0.014 & 1.929 & 0.414 & 48 & 1 & 0.213 & 0.120 & 0.444 & 0.224 \\
\hline 15 & 6 & 0.632 & 1.988 & 0.963 & 2.417 & 49 & 2 & 0.604 & 0.005 & 0.102 & 1.290 \\
\hline$\ldots$ & & & & & & 50 & 1 & 0.029 & 0.003 & 0.921 & 0.047 \\
\hline
\end{tabular}


(a)

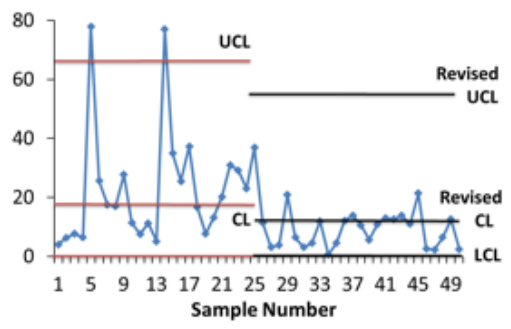

(b)

(c)

Figure 3. Control charts for the low quantity order, dress model a) Demerit chart, b) Attribute c-chart, c) Attribute u-chart

(a)

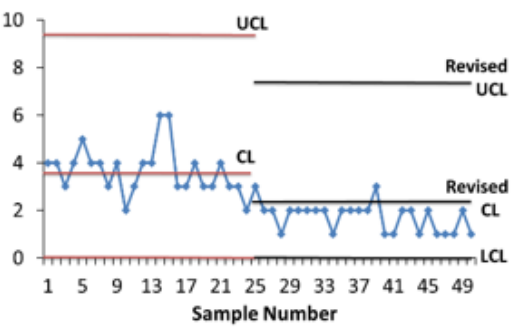

UCL

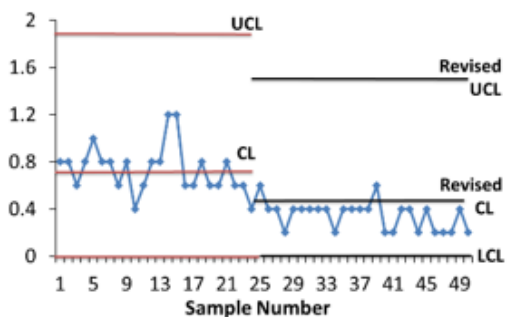

Sample Number

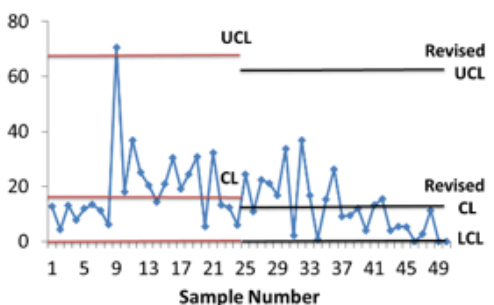

(b)

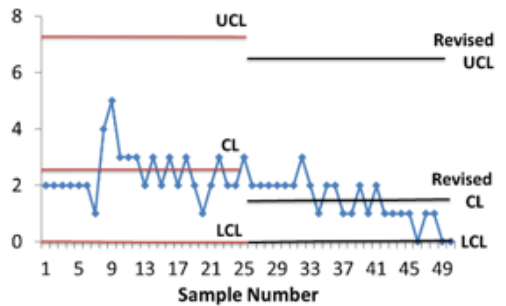

(c)

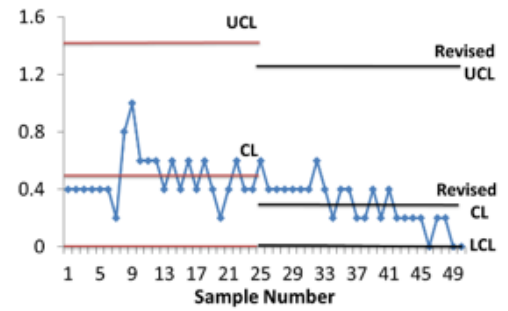

Figure 4. Control charts for the high quantity order, dress model a) Demerit chart, b) Attribute c-chart, c) Attribute u-chart

(a)

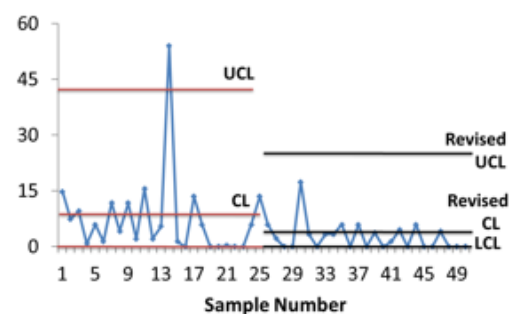

(b)

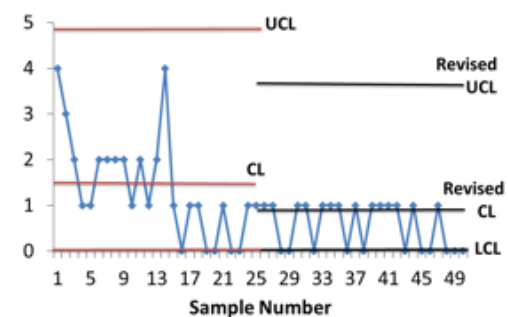

(c)

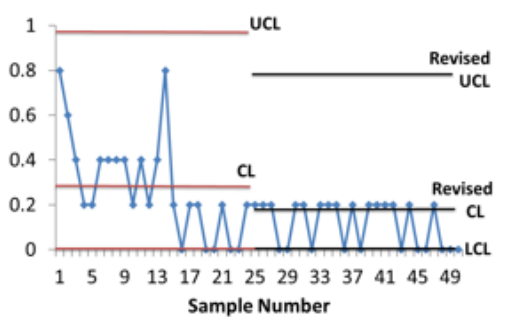

Figure 5. Control charts for the low quantity order, blouse model a) Demerit chart, b) Attribute c-chart, c) Attribute u-chart

(a)

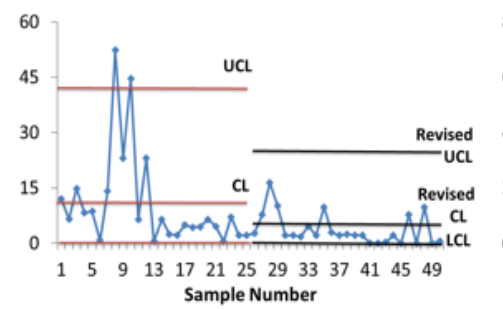

(b)

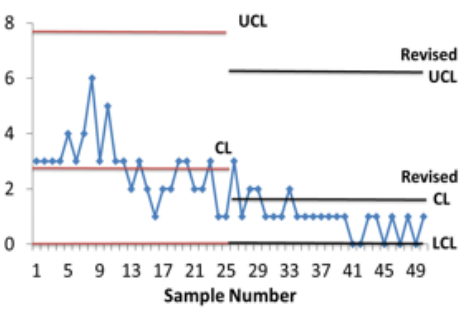

(c)

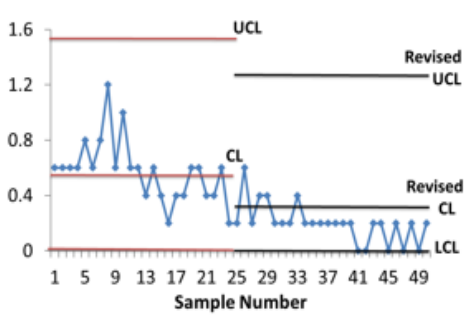

Figure 6. Control charts for the high quantity order, blouse model a) Demerit chart, b) Attribute c-chart, c) Attribute u-chart

By reviewing the quality control reports of the products produced by the company, the number of repairs, the number of scraps for the three product types, dress, blouse, and skirts were obtained. Repair times were determined for the dress, blouse, and skirt by asking the quality supervisor, tape chief, production manager, and production engineer. Accordingly defects were clustered by fuzzy c-means into 4 classes. In Table 6, the number of defects per class of each product type is shown by assigning the defect to the class which has the maximum membership value.

At the end of the clustering, cluster membership values were found for each defect. These clusters were matched to clusters showing the degree of importance of the defect 
classes of the demerit control charts. The frequency and size of sampling are important in the process of control chart design. In general, larger samples make it easier to detect small changes in the process. The ideal situation for detecting defects is to take frequent and large examples in the control chart design, but this is not economical due to increasing inspection costs. In the study, data were collected with an interval of one hour and a sample size of 5 .

In order to test the proposed method $\mathrm{u}$-chart, c-chart and demerit control chart for 6 different process instances were established in a textile operation. A total of 250 samples were taken for 5 days for each process instance examined. In the demerit control chart, demerit points were determined according to the cluster membership level of each defect. After each defect was classified, the defect weights were taken as 100, 50, 10, 1 for groups A, B, C, and $\mathrm{D}$, respectively. The total demerit point of each defect was found by multiplying the defect weights, the total number of defects and the cluster membership value of the group to which it belonged.

We compared the results of the instances of the case study with the past production statistics in terms of the average scraps and the repair rates. The data used to compare the results of fuzzy c-means demerit control charts with the past production statistics were taken from the produced orders in the last 6 months. It was observed that both the scrap and the repair rates were decreased when the proposed method of demerit control charts with fuzzy cmeans clustering was used. The results were given in Table 7 and Table 8. Orders examined were selected to be high and low quantity orders in each product type. Order size was selected to be high and low quantity for each product type. Order size affects the rework and scrap percentage of order because there exist more defects in the production line generally at the beginning of the production. As the operators learn the operations, the quality and the cycle time of the production improves. Thus, the expected percentage of the quality problems such as rework and scrap decrease for high quantity orders irrelevant to the quality control efforts. Moreover, some models are more complex which require complex production operations. Model complexity also increases the quality problems of order. Here, we classify each order with two levels of the order size and the model complexity, namely as high and low. The results show that for almost all types of orders, the proposed demerit quality control system improved the reworks and scraps compared to those of the average of the past orders. Only one of the orders did not result in improvement. This is due to the very complex model style causing the production to be extremely difficult.

Table 6. Number of elements per class for each product group

\begin{tabular}{cccc}
\hline \multirow{2}{*}{ Class Type } & \multicolumn{3}{c}{ Number of elements } \\
\cline { 2 - 4 } A & Dress & Blouse & Skirt \\
B & 14 & 6 & 10 \\
C & 4 & 5 & 3 \\
D & 19 & 32 & 19 \\
Total & 23 & 17 & 18 \\
\end{tabular}

Table 7. Comparison of reworks results of demerit control charts using fuzzy c-means with the past manufacturing orders

\begin{tabular}{|c|c|c|c|c|c|}
\hline $\begin{array}{c}\text { Product } \\
\text { type }\end{array}$ & $\begin{array}{c}\text { Order } \\
\text { quantity }\end{array}$ & $\begin{array}{c}\text { Order } \\
\text { complexity }\end{array}$ & $\begin{array}{l}\text { Average reworks } \\
\% \text { of past orders }\end{array}$ & $\begin{array}{l}\text { \% of reworks with clustering } \\
\text { based demerit control charts }\end{array}$ & $\begin{array}{l}\text { Improvement } \\
\% \text { in reworks }\end{array}$ \\
\hline Dress $1^{\text {st }}$ & Low & High & 20.75 & 16.76 & 19.23 \\
\hline Dress $2^{\text {nd }}$ & High & Low & 13.93 & 8.53 & 38.77 \\
\hline Blouse $1^{\text {st }}$ & Low & Low & 19.65 & 6.76 & 65.60 \\
\hline Blouse $2^{\text {nd }}$ & High & High & 11.39 & 8.04 & 29.41 \\
\hline Skirt $1^{\text {st }}$ & Low & Low & 18.03 & 15.13 & 16.08 \\
\hline Skirt $2^{\text {nd }}$ & High & High & 15.38 & 13.96 & 9.23 \\
\hline
\end{tabular}

Table 8. Comparison of scraps results of demerit control charts using fuzzy c-means with the past manufacturing orders

\begin{tabular}{lccccc}
\hline $\begin{array}{c}\text { Product } \\
\text { type }\end{array}$ & $\begin{array}{c}\text { Order } \\
\text { quantity }\end{array}$ & $\begin{array}{c}\text { Order } \\
\text { complexity }\end{array}$ & $\begin{array}{c}\text { Average scraps } \\
\text { \% of past orders }\end{array}$ & $\begin{array}{c}\text { \% of scraps with clustering } \\
\text { based demerit control charts }\end{array}$ & $\begin{array}{c}\text { Improvement } \\
\text { \% in scraps }\end{array}$ \\
\hline Dress 1 $^{\text {st }}$ & Low & High & 1.68 & 1.48 & 11.90 \\
Dress 2 $^{\text {nd }}$ & High & Low & 0.93 & 0.76 & 18.28 \\
Blouse 1 $^{\text {st }}$ & Low & Low & 1.24 & 0.38 & 69.35 \\
Blouse 2 $^{\text {nd }}$ & High & High & 0.77 & 0.25 & 67.53 \\
Skirt 1 1 $^{\text {st }}$ & Low & Low & 1.26 & 0.44 & 65.08 \\
Skirt 2 $^{\text {nd }}$ & High & High & 0.74 & 1.19 & -60.81 \\
\hline
\end{tabular}




\section{CONCLUSION}

Defects in products are not always of the same severity. The observed defects can be grouped according to their level of influence on the quality of products and the qualityrelated costs. In this study, we proposed a method that provides a more precise process control at low cost by introducing weights of different defect classes and membership of defects to defect classes. In the proposed method, the fuzzy c-means method was used. The defect types were clustered according to the number of scrap, repair number and repair time parameters. Cluster membership values were found for each defect. Then, we designed demerit control charts with these membership values. The results of the demerit charts were found to be more sensitive and useful compared to past data.

In order to test the proposed method, 6 different process instances were examined in a textile operation. Signals that were outside of the control limits were investigated, looking

\section{REFERENCES}

1. Montgomery, DC. 2009. Introduction to Statistical Quality Control, 6th edition. United States of America, New York, John Wiley and Sons.

2. Ertuğrul İ, Özçil A. 2014. The application of 'p' and 'p-CUSUM charts into textile sector in the statistical quality control process. Tekstil ve Konfeksiyon 24(1), 9-14

3. Yıldız TÖ, Vahaplar SŞ. 2015. An application on fancy shirting fabric production through distribution-free quality control charts. Tekstil ve Konfeksiyon 25(2), 97-103.

4. Lim SAH, Antony J, He Z, Arshed N. 2017. Critical observations on the statistical process control implementation in the UK food industry: A survey. International Journal of Quality \& Reliability Management 34(5), 684-700. https://doi.org/10.1108/IJQRM-03-2015-0035

5. Senturk S, Erginel N, Kaya I, Kahraman C. 2014. Fuzzy exponentially weighted moving average control chart for univariate data with a real case application. Applied Soft Computing 22, 1-10. https://doi.org/10.1016/j.asoc.2014.04.022

6. Tuerhong G, Kim SB. 2015. Comparison of Novelty Score Based Multivariate Control Charts. Communications in Statistics-Simulation and Computation 44(5), 1126-1143. https://doi.org/10.1080/ 03610918.2013 .809098

7. Li CI, Pan JN, Huang MH. 2019. A New Demerit Control Chart for Monitoring the Quality of Multivariate Poisson Processes. Journal of Applied Statistics 46(4), 680-699. https://doi.org/10.1080/ 02664763. 2018.1510477

8. Rasouli O, Zarei MH. 2016. Monitoring and reducing patient dissatisfaction: A case study of an Iranian public hospital. Total Quality Management \& Business Excellence 27(5-6), 531-559. https://doi.org/10.1080/14783363.2015.1016869

9. Niazmand K., Mirzazadeh A, Rezaie K. 2014. A fuzzy SQFE approach in supplier's performance monitoring. International Journal of Production Research 52(22), 6841-6862. https://doi.org/ 10.1080/00207543.2014.919417

10. Nembhard DA, Nembhard HB. 2000. A Demerits Control Chart For Autocorrelated Data. Quality Engineering 13(2), 179-190. http://doi.org/10.1080/08982110108918640 for potential assignable causes. Any assignable cause that was identified was worked on by engineering and operating personnel in an effort to eliminate them. When c-chart, uchart, and demerit control charts were compared, c-chart and $\mathrm{u}$-chart detected the problems in the process in two process instances, while the demerit control chart detected the process problems in all 6 process instances examined. When the case study results were compared with the past production data, it was seen that the repair and scrap rates decreased. The proposed method is a more sensitive method compared to traditional demerit control charts and $\mathrm{c}$ and $\mathrm{u}$ attribute control charts. As a result, a remarkable decrease in the rework and scrap rates can be achieved using this method.

In future studies, the clustering of defects can be tested using different clustering schemes such as k-means, selforganizing maps. Moreover, multivariate quality-control approaches can also be compared with the demerit systems.

11. Shu MH., Chiu CC, Nguyen TL, Hsu BM. 2014. A demerit-fuzzy rating system, monitoring scheme and classification for manufacturing processes. Expert Systems with Applications 41(17), 7878-7888. https://doi.org/10.1016/j.eswa.2014.06.035

12. Ho SL, Xie M, Goh TN. 2003. Process Monitoring Strategies for Surface Mount Manufacturing Processes. International Journal of Flexible Manufacturing Systems 15(2), 95-112. https://doi.org/ 10.1023/A:1024432723561

13. Hou S, Wang H, Feng S. 2016. Attribute Control Chart Construction Based on Fuzzy Score Number. Symmetry 8(12), 139. https://doi.org/10.3390/sym8120139

14. Chen LH. 2005. A demerit control chart with linguistic weights Journal of Intelligent Manufacturing 16(3), 349-359. https://doi.org/ 10.1007/s10845-005-7028-1

15. Cheng CB. 2005. Fuzzy process control: construction of control charts with fuzzy numbers. Fuzzy Sets and Systems 154(2), 287-303. https://doi.org/10.1016/j.fss.2005.03.002

16. Yinelek H. 2017. Design of Demerit Control Chart by Fuzzy CMeans Method and an Application in Textile Sector. MSc Thesis, Istanbul Technical University, Institute of Science and Technology, Istanbul.

17. Ansari A, Riasi A. 2016. Customer Clustering Using a Combination of Fuzzy C-Means and Genetic Algorithms. International Journal of Business and Management 11(7), 59-66. http://doi.org/10.5539/ijbm.v11n7p59

18. Dodge HF. 1928. A method of rating a manufactured product. The Bell System Technical Journal 7(2), 350-368. https://doi.org/ 10.1002/j.1538-7305.1928.tb01229.x

19. Chimka JR, Arispe PVC. 2006. New Demerit Control Limits for Poisson Distributed Defects. Quality Engineering 18(4), 461-467. https://doi.org/10.1080/08982110600817235

20. Jones LA, Woodall WH, Conerly MD 1999. Exact Properties of Demerit Control Charts. Journal of Quality Technology 31(2), 207216. https://doi.org/10.1080/00224065.1999.11979915 